\title{
Azo-Hydrazone Tautomerism and Antimicrobial activity of New substituted Imidazolines and Perimidines
}

\author{
Thoraya A. Farghaly ${ }^{a, b^{\star}}$ Magda A. Abdallah ${ }^{a}$ and Mohamed R. Abdel Aziz ${ }^{a}$ \\ a) Department of Chemistry, Faculty of Science, Cairo University, Giza, 12613, Egypt. \\ b) Department of Chemistry, Faculty of Applied Science, Umm Al-Qura University, Makkah Almukkarramah, \\ Saudi Arabia. \\ e.mail: thoraya-f@hotmail.com
}

\section{ABSTRACT}

Two new series of 2-\{1-[(substitutedphenyl)-hydrazono]-2-oxo-2-phenyl-ethyl\}-5,5-diphenyl-3,5-dihydro-imidazol-4-one and $(1 \mathrm{H}$ perimidin-2-yl)-[(substitutedphenyl)-hydrazono]-acetic acid ethyl ester were prepared by coupling the diazonium salt of aniline and its derivatives with 2-(2-oxo-2-phenyl-ethylidene)-5,5-diphenyl-imidazolidin-4-one or ethyl 3-dimethylamino-2$(1 \mathrm{H}$-perimidin-2-yl)-propenoate in ethanolic sodium hydroxide solution. The structures of all the newly synthesized compounds were confirmed by spectral (IR, ${ }^{1} \mathrm{H}$ NMR, mass) spectra , and X-ray crystallographic and elemental analyses. Also, the azo-hydrazone tautomerism of these compounds was discussed. In addition, all the newly synthesized compounds were screened for their antibacterial and antifungal activity and the results obtained indicated that some of these compounds exhibited excellent activity.

\section{Keywords}

X-ray crystallography; perimidines; imidazolines; azo-hydrazone tautomerism; anti-microbial activity.

\section{Council for Innovative Research}

Peer Review Research Publishing System

\section{Journal: Journal of Advances in Chemistry}

Vol. 10, No. 5

editorjaconline@gmail.com

www.cirjac.com 


\section{INTRODUCTION}

In recent years, arylazo derivatives of various heterocyclic systems have been the subject of intense research by organic chemists [1] and dye manufactures [2]. These colouring matters were found useful in the fields of material sciences and theoretical chemistry [3]. For example, many of such azo dyes have been extensively used as dyes in various fields such as dyeing of textile fibers, coloured plastics, biological-medical studies and advanced applications in organic synthesis [4]. Recently, applications of such colouring materials to high technology have been attracting much attention. Dyes are used in various fields such as printing, electronic photography, color formers, liquid crystal displays, laser technology, data storage and solar energy conversion [5]. In addition, some of such dyes have found use as nonlinear optical (NLO) materials. They have potential use in optical communications, information processing, frequency doubling and integrated optics [6]. In the light of these findings and as a part of our comprehensive program directed for synthesis and elucidation of the tautomeric structures of arylazo-heterocycles [7-15], it was interesting to study herein the synthesis of two new series of 2-\{1-[(substitutedphenyl)-hydrazono]-2-oxo-2-phenyl-ethyl\}-5,5-diphenyl-3,5-dihydro-imidazol-4one and (1 H-Perimidin-2-yl)-[(substitutedphenyl)-hydrazono]-acetic acid ethyl ester which have not been reported hitherto. Our interest in such azo derivatives is to elucidate their tautomeric structure prior exploring their utility. Since each of such dyes can has one or more of the six tautomeric forms 5A-F or three tautomeric forms 10A-C depicted in Schemes 2 and 3. The knowledge of the actual tautomeric form(s) of azo dyes in solution and the solid phase is a quite important factor for the industrial and biological applications of azo dyes. Also, the antimicrobial activity of the newly synthesized compounds was evaluated,based on the previous reports which indicated that compounds containing imidazole, perimidine and hydrazone moieties have interesting biological activity such as antimicrobial [16-19], analgesic [20], anti-inflammatory [21] and anti-cancer $[22,23]$ activities.

\section{Experimental}

\section{Materials}

Melting points were determined on a Gallenkamp apparatus and are uncorrected. IR spectra were recorded in potassium bromide using Perkin Elmer FTIR 1650 and Pye-Unicam SP300 infrared spectrophotometers. ${ }^{1} \mathrm{H}$ NMR spectra were recorded in deuterated DMSO- $\mathrm{d}_{6}$ using a Varian Gemini 200 NMR spectrometer. Mass spectra were recorded on a GCMS-QP 1000 EX Shimadzu and GCMS 5988-A HP spectrometers. Electronic absorption spectra were recorded on Perkin-Elmer Lambada 40 spectrophotometer. Elemental analyses were carried out at the Microanalytical Laboratory of Cairo University, Giza, Egypt. Antimicrobial activity was carried out at the Regional Center for Mycology and Biotechnology at Al-Azhar University, Cairo, Egypt.

\section{Crystallographic analysis}

The crystals were mounted on a glass fiber. All measurements were performed on an ENRAF NONIUS FR 590 . The data were collected at a temperature of $25^{\circ} \mathrm{C}$ using the $\omega$ scanning technique to a maximum of a 20 of $22.986^{\circ}$. The structure was solved by direct method using SIR 92 and refined by full-matrix least squares. Non-hydrogen atoms were refined anisotropically. Hydrogen atoms were located geometrically and were refined isotropically.

\section{Crystal data}

For compound 5f: $\mathrm{C}_{29} \mathrm{H}_{21} \mathrm{CIN}_{4} \mathrm{O}_{2}, \mathrm{M}=492.95$, Monoclinic, $\mathrm{a}=8.6867$ (3) $\AA$, $\mathrm{b}=25.8621(8) \AA, c=11.0795(3) \AA$, $v=$ $2483.55(13) \AA^{3}, \alpha=90.00^{\circ}, \beta=93.820(2)^{\circ}, \quad y=90.00^{\circ}$, space group: $P 121 / \mathrm{n} 1, Z=4, \quad D_{x}=1.318 \mathrm{~g} / \mathrm{cm} 3,15481$ reflections measured, $\theta_{\max }=66.64^{\circ}$. Figure 1 illustrates the structure as determined [24].

\section{2-(2-oxo-2-phenyl-ethylidene)-5,5-diphenyl-imidazolidin-4-one (3)}

A solution of compound $2(1.93 \mathrm{~g}, 5 \mathrm{mmol})$ in diphenyl ether $(10 \mathrm{ml})$ was heated in an oil bath at $200-210 \stackrel{\circ}{\circ}$ for $10 \mathrm{~min}$, then cooled. To the cold mixture was added ether where a white solid product precipitated. After complete precipitation, the solid product was collected, washed with ether and crystallized from ethanol to give $3 \mathrm{mp}>300{ }^{\circ} \mathrm{C}$ [25].

\section{Synthesis of ethyl 3-dimethylamino-2-(1H-perimidin-2-yl)-propenoate (7)}

A mixture of 6 [26] $(2.64 \mathrm{~g}, 10 \mathrm{mmol})$ and dimethylformamide-dimethylacetal $(1.2 \mathrm{~g}, 10 \mathrm{mmol})$ in dry toluene $(15 \mathrm{~mL})$ was refluxed for $5 \mathrm{hrs}$. After cooling, the precipitate was collected by filtration and crystallized from dioxane as red solid, $(89 \%$ yield), mp 270-272 으; IR (KBr) $v_{\max } 3225(\mathrm{NH}), 1710(\mathrm{C}=\mathrm{O}), 1554(\mathrm{C}=\mathrm{N}) \mathrm{cm}^{-1}$; ${ }^{1} \mathrm{H}$ NMR (DMSO-d $) \delta 1.33(\mathrm{t}, \mathrm{J}=7 \mathrm{~Hz}$, $\left.3 \mathrm{H}, \mathrm{CH}_{3}\right), 2.85,2.90\left(2 \mathrm{~s}, 6 \mathrm{H}, 2 \mathrm{CH}_{3}\right), 4.24\left(\mathrm{q}, J=7 \mathrm{~Hz}, 2 \mathrm{H}, \mathrm{CH}_{2}\right), 6.80-8.43(\mathrm{~m}, 6 \mathrm{H}, \mathrm{ArH}), 8.72(\mathrm{~s}, 1 \mathrm{H},=\mathrm{CH}), 10.82(\mathrm{~s}, 1 \mathrm{H}$, $\mathrm{NH})$. MS m/z (\%) $310\left(\mathrm{M}^{+}+1,20\right), 309\left(\mathrm{M}^{+}, 24\right), 263(56), 192(44), 57(100), 56$ (48). Anal. Calcd. for $\mathrm{C}_{18} \mathrm{H}_{19} \mathrm{~N}_{3} \mathrm{O}_{2}(309.36)$ : C, 69.88; H, 6.19; N, 13.58. Found: C, 69.69; H, 6.02; N, 13.38\%

\section{Coupling reaction of compounds 3,6 and 7 with arenediazonium salts:}

General procedure: To a stirred solution of the appropriate compounds 3, 6 or 7 (10 mmol) in ethanol (50 ml) was added sodium hydroxide $(0.4 \mathrm{~g}, 10 \mathrm{mmol})$ and the mixture was cooled in an ice bath to $0-5 \stackrel{\circ}{\circ}$. To the resulting solution, while being stirred, was added dropwise over a period of $20 \mathrm{~min}$ the solution of the appropriate arenediazonium chloride which prepared as usual by diazotizing the respective aniline $(10 \mathrm{mmol})$ in hydrochloric acid $(6 \mathrm{M}, 6 \mathrm{ml})$ with sodium nitrite (1 M, $10 \mathrm{ml}$ ). The whole mixture was then left in a refrigerator overnight. The precipitated solid was collected, washed with water and finally crystallized from the appropriate solvent to give the respective hydrazones 5a-j and azo compounds 10a-i, respectively. The physical constants of the products 5a-j and 10a-i together with their spectral data are depicted bellow: 


\section{2-\{1-[(4-Methoxyphenyl)hydrazono]-2-oxo-2-phenyl-ethyl\}-5,5-diphenyl-3,5-dihydro-imidazol-4-one (5a)}

Yellow solid, (85\% yield), $\mathrm{mp}>300^{\circ} \mathrm{C}$ (Ethanol); IR (KBr) $\mathrm{v}_{\max } 3447,3298(2 \mathrm{NH}), 1734,1637(2 \mathrm{C}=\mathrm{O}), 1585(\mathrm{C}=\mathrm{N}) \mathrm{cm}^{-1}$; ${ }^{1} \mathrm{H}$ NMR (DMSO-d $\left.\mathrm{d}_{6}\right) \delta 3.57\left(\mathrm{~s}, 3 \mathrm{H}, \mathrm{OCH}_{3}\right), 7.34-7.86(\mathrm{~m}, 19 \mathrm{H}, \mathrm{ArH}), 10.54(\mathrm{~s}, 1 \mathrm{H}, \mathrm{NH}), 11.77(\mathrm{~s}, 1 \mathrm{H}, \mathrm{NH}) . \mathrm{MS} \mathrm{m} / \mathrm{z}(\%) 488$ $\left(\mathrm{M}^{+}, 15\right), 473$ (19), 400 (21), 354 (90), 353 (100), 334 (25), 324 (21), 307 (21), 293 (23), 248 (25), 206 (22), 198 (22), 165 (35), 153 (26), 105 (26), 77 (82). Anal. Calcd. for $\mathrm{C}_{30} \mathrm{H}_{24} \mathrm{~N}_{4} \mathrm{O}_{3}$ (488.54): C, 73.76; $\mathrm{H}, 4.95 ; \mathrm{N}, 11.47$. Found: $\mathrm{C}, 73.59 ; \mathrm{H}$, $4.78 ; \mathrm{N}, 11.21 \%$

\section{2-\{1-[(4-Methylphenyl)hydrazono]-2-oxo-2-phenyl-ethyl\}-5,5-diphenyl-3,5-dihydro-imidazol-4-one (5b)}

Yellow solid, (80\% yield), mp 290-292 ㅇ (Ethanole/Dioxane); IR (KBr) $v_{\max } 3445,3298(2 \mathrm{NH}), 1731,1636(2 \mathrm{C}=\mathrm{O}), 1581$ $(\mathrm{C}=\mathrm{N}) \mathrm{cm}^{-1} ;{ }^{1} \mathrm{H}$ NMR (DMSO-d $\left.\mathrm{d}_{6}\right) \delta 2.49\left(\mathrm{~s}, 3 \mathrm{H}, \mathrm{CH}_{3}\right), 7.35-7.86(\mathrm{~m}, 19 \mathrm{H}, \mathrm{ArH}), 10.54(\mathrm{~s}, 1 \mathrm{H}, \mathrm{NH}), 11.74(\mathrm{~s}, 1 \mathrm{H}, \mathrm{NH}) . \mathrm{MS}$ $\mathrm{m} / \mathrm{z}(\%) 473\left(\mathrm{M}^{+}+1,13\right), 472\left(\mathrm{M}^{+}, 20\right), 414(17), 368(20), 354$ (100), $316(17), 307$ (12), 294 (22), 307 (21), $294(22), 272$ (15), 244 (24), 221 (56), 182 (39), 176 (16), 165 (33), 153 (10), 147 (15), 114 (22), 105 (68), 73 (22). Anal. Calcd. for $\mathrm{C}_{30} \mathrm{H}_{24} \mathrm{~N}_{4} \mathrm{O}_{2}$ (472.54): C, 76.25; $\mathrm{H}, 5.12 ; \mathrm{N}, 11.86$. Found: $\mathrm{C}, 76.04 ; \mathrm{H}, 5.31 ; \mathrm{N}, 11.67 \%$

\section{2-\{1-[(3-Methylphenyl)hydrazono]-2-oxo-2-phenyl-ethyl\}-5,5-diphenyl-3,5-dihydro-imidazol-4-one (5c)}

Yellow solid, (79\% yield), $\mathrm{mp}>300^{\circ} \mathrm{C}$ (Ethanol); IR (KBr) $\mathrm{V}_{\max } 3444,3298(2 \mathrm{NH}), 1734,1636(2 \mathrm{C}=\mathrm{O}), 1585(\mathrm{C}=\mathrm{N}) \mathrm{cm}^{-1}$; ${ }^{1} \mathrm{H}$ NMR (DMSO-d $)_{6} \delta 2.29$ (s, 3H, $\left.\mathrm{CH}_{3}\right), 7.35-7.86(\mathrm{~m}, 19 \mathrm{H}, \mathrm{ArH}), 10.54(\mathrm{~s}, 1 \mathrm{H}, \mathrm{NH}), 11.79(\mathrm{~s}, 1 \mathrm{H}, \mathrm{NH}) . \mathrm{MS} \mathrm{m} / \mathrm{z}(\%) 472$ $\left(\mathrm{M}^{+}, 9\right), 354$ (80), 276 (13), 249 (43), 234 (26), 221 (34), 181 (20), 167 (44), 165 (44), 146 (23), 105 (96), 77 (100). Anal. Calcd. for $\mathrm{C}_{30} \mathrm{H}_{24} \mathrm{~N}_{4} \mathrm{O}_{2}$ (472.54): C, 76.25; $\mathrm{H}, 5.12 ; \mathrm{N}, 11.86$. Found: C, 76.10; H, 5.03; N, $11.72 \%$.

\section{2-\{1-(Phenylhydrazono)-2-oxo-2-phenyl-ethyl\}-5,5-diphenyl-3,5-dihydro-imidazol-4-one (5d)}

Yellow solid, (88\% yield), mp 240-242 ํ (Ethanol); IR (KBr) $v_{\max } 3441,3296(2 \mathrm{NH}), 1733,1636(2 \mathrm{C}=\mathrm{O}), 1585(\mathrm{C}=\mathrm{N}) \mathrm{cm}$ 1; ${ }^{1} \mathrm{H}$ NMR (DMSO-d $\left.\mathrm{d}_{6}\right) \delta 7.39-7.83(\mathrm{~m}, 20 \mathrm{H}, \mathrm{ArH}), 10.60(\mathrm{~s}, 1 \mathrm{H}, \mathrm{NH}), 11.77(\mathrm{~s}, 1 \mathrm{H}, \mathrm{NH}) . \mathrm{MS} \mathrm{m} / \mathrm{z}(\%) 458\left(\mathrm{M}^{+}, 6\right), 457(9)$, 354 (22), 325 (23), 277 (14), 249 (25), 221 (30), 182 (33), 165 (45), 146 (15), 128 (20), 105 (61), 77 (100). Anal. Calcd. for $\mathrm{C}_{29} \mathrm{H}_{22} \mathrm{~N}_{4} \mathrm{O}_{2}$ (458.51): C, 75.97; $\mathrm{H}, 4.84 ; \mathrm{N}, 12.22$. Found: $\mathrm{C}, 75.69 ; \mathrm{H}, 4.65 ; \mathrm{N}, 12.14 \%$.

\section{2-\{1-[(3-Chlorophenyl)hydrazono]-2-oxo-2-phenyl-ethyl\}-5,5-diphenyl-3,5-dihydro-imidazol-4-one (5e)}

Orange solid, (75\% yield), $\mathrm{mp} 116-118^{\circ} \mathrm{C}$ (Ethanol); IR (KBr) $v_{\max } 3427,3312(2 \mathrm{NH}), 1736,1627(2 \mathrm{C}=\mathrm{O}), 1525(\mathrm{C}=\mathrm{N}) \mathrm{cm}$ 1; ${ }^{1} \mathrm{H}$ NMR (DMSO-d $)$ ס 7.21-7.55 (m, 19H, ArH), $11.16(\mathrm{~s}, 1 \mathrm{H}, \mathrm{NH}), 11.84(\mathrm{~s}, 1 \mathrm{H}, \mathrm{NH}) . \mathrm{MS} \mathrm{m} / \mathrm{z}(\%) 495\left(\mathrm{M}^{+}+2,10\right), 494$ $\left(\mathrm{M}^{+}+1,29\right), 493\left(\mathrm{M}^{+}, 43\right), 366$ (100), 323 (27), 354 (38), $288(17), 260$ (12), 234 (20), 194 (2), 182 (22), 165 (26), $127(22)$, 105 (88), 77 (53). Anal. Calcd. for $\mathrm{C}_{29} \mathrm{H}_{21} \mathrm{ClN}_{4} \mathrm{O}_{2}$ (492.96): C, 70.66; $\mathrm{H}, 4.29 ; \mathrm{N}, 11.37$. Found: $\mathrm{C}, 70.52 ; \mathrm{H}, 4.15 ; \mathrm{N}$, $11.14 \%$.

\section{2-\{1-[(4-Chlorophenyl)hydrazono]-2-oxo-2-phenyl-ethyl\}-5,5-diphenyl-3,5-dihydro-imidazol-4-one (5f)}

Yellow solid, (83\% yield), mp 210-212 으 (Ethanol); IR (KBr) $v_{\max } 3312(2 \mathrm{NH}), 1734,1635(2 \mathrm{C}=\mathrm{O}), 1530(\mathrm{C}=\mathrm{N}) \mathrm{cm}^{-1} ;{ }^{1} \mathrm{H}$ NMR (DMSO-d $\left.\mathrm{d}_{6}\right) \delta$ 7.16-7.91 (m, 19H, ArH), $11.15(\mathrm{~s}, 1 \mathrm{H}, \mathrm{NH}), 11.84(\mathrm{~s}, 1 \mathrm{H}, \mathrm{NH}) . \mathrm{MS} \mathrm{m} / \mathrm{z}(\%) \mathrm{MS} \mathrm{m} / \mathrm{z}(\%) 495\left(\mathrm{M}^{+}+2,2\right)$, $494\left(\mathrm{M}^{+}+1,3\right), 493\left(\mathrm{M}^{+}, 6\right), 492(6), 417(9), 366(71), 260(15), 234(18), 182(24), 165(39), 127(20), 105(85), 77(100)$. Anal. Calcd. for $\mathrm{C}_{29} \mathrm{H}_{21} \mathrm{ClN}_{4} \mathrm{O}_{2}$ (492.96): C, 70.66; $\mathrm{H}, 4.29 ; \mathrm{N}, 11.37$. Found: $\mathrm{C}, 70.48 ; \mathrm{H}, 4.10 ; \mathrm{N}, 11.18 \%$

\section{2-\{1-[(3-Nitrophenyl)hydrazono]-2-oxo-2-phenyl-ethyl\}-5,5-diphenyl-3,5-dihydro-imidazol-4-one (5g)}

Orange solid, (68\% yield), $\mathrm{mp} 186-188^{\circ} \mathrm{C}$ (Ethanol); IR (KBr) $\mathrm{v}_{\max } 3434,3220(2 \mathrm{NH}), 1743,1647(2 \mathrm{C}=\mathrm{O}), 1532(\mathrm{C}=\mathrm{N}) \mathrm{cm}$ '; ${ }^{1} \mathrm{H}$ NMR (DMSO-d $)$ $)$ 7.25-7.85 (m, 19H, ArH), 11.25 (s, 1H, NH), $11.92(\mathrm{~s}, 1 \mathrm{H}, \mathrm{NH}) . \mathrm{MS} \mathrm{m} / \mathrm{z}(\%) 503\left(\mathrm{M}^{+}, 39\right), 502$ (26), 474 (3), 411 (3), 366 (65), 323 (17), 288 (10), 260 (9), 234 (12), 165 (19), 105 (100), 77 (65). Anal. Calcd. for $\mathrm{C}_{29} \mathrm{H}_{21} \mathrm{~N}_{5} \mathrm{O}_{4}$ (503.51): C, 69.18; $\mathrm{H}, 4.20 ; \mathrm{N}, 13.91$. Found: C, 69.04; H, 4.09; N, 13.76\%.

\section{2-\{1-[(4-Nitrophenyl)hydrazono]-2-oxo-2-phenyl-ethyl\}-5,5-diphenyl-3,5-dihydro-imidazol-4-one (5h)}

Dark yellow solid, (83\% yield), $\mathrm{mp}>300 \stackrel{\circ}{\circ}$ (Ethanol/Dioxane); IR (KBr) $\mathrm{V}_{\max } 3437,3299(2 \mathrm{NH}), 1738,1636(2 \mathrm{C}=\mathrm{O}), 1572$ $(\mathrm{C}=\mathrm{N}) \mathrm{cm}^{-1} ;{ }^{1} \mathrm{H}$ NMR (DMSO-d $)$ ס 7.16-8.25 (m, 19H, ArH), $10.54(\mathrm{~s}, 1 \mathrm{H}, \mathrm{NH}), 11.92(\mathrm{~s}, 1 \mathrm{H}, \mathrm{NH}) . \mathrm{MS} \mathrm{m} / \mathrm{z}(\%) 503\left(\mathrm{M}^{+}\right.$, 16), 366 (36), 354 (33), 323 (11), 249 (14), 234 (14), 182 (23), 165 (30), 105 (81), 77 (100). Anal. Calcd. for $\mathrm{C}_{29} \mathrm{H}_{21} \mathrm{~N}_{5} \mathrm{O}_{4}$ (503.51): C, 69.18; H, 4.20; N, 13.91. Found: C, 68.99; H, 4.12; N, 13.83\%.

\section{2-\{1-[(4-acetylphenyl)hydrazono]-2-oxo-2-phenyl-ethyl\}-5,5-diphenyl-3,5-dihydro-imidazol-4-one (5i)}

Yellow solid, (91\% yield), mp 260-262 ㅇ (Ethanol); IR (KBr) $v_{\max }$ 3462, $3264(2 \mathrm{NH}), 1744,1672,1644$ (3C=O), 1536 $(\mathrm{C}=\mathrm{N}) \mathrm{cm}^{-1}$; ${ }_{1} \mathrm{H}$ NMR (DMSO-d $) \delta 2.49\left(\mathrm{~s}, 3 \mathrm{H}, \mathrm{COCH}_{3}\right), 7.16-8.00(\mathrm{~m}, 19 \mathrm{H}, \mathrm{ArH}), 11.34(\mathrm{~s}, 1 \mathrm{H}, \mathrm{NH}), 11.83(\mathrm{~s}, 1 \mathrm{H}, \mathrm{NH})$. MS m/z (\%) $500\left(\mathrm{M}^{+}, 8\right), 499$ (6), 354 (65), 325 (18), 249 (27), 234 (19), 221 (24), 206 (14), 182 (31), 165 (34), 145 (11), 105 (72), 77 (100). Anal. Calcd. for $\mathrm{C}_{31} \mathrm{H}_{24} \mathrm{~N}_{4} \mathrm{O}_{3}$ (500.55): C, 74.38; H, 4.83; N, 11.19. Found: C, 74.17; H, 4.65; N, $11.03 \%$.

\section{2-\{1-[(4-Ethoxycarbonylphenyl)hydrazono]-2-oxo-2-phenyl-ethyl\}-5,5-diphenyl-3,5-dihydro-imidazol-4-one (5j)}

Yellow solid, (82\% yield), mp 234-236 ํㅜ; IR (KBr) $\mathrm{v}_{\max } 3431,3303(2 \mathrm{NH}), 1734,1729,1636(3 \mathrm{C}=\mathrm{O}), 1525(\mathrm{C}=\mathrm{N}) \mathrm{cm}^{-1} ;{ }^{1} \mathrm{H}$ NMR (DMSO-d $\left.)_{6}\right) \delta 1.30\left(\mathrm{t}, J=7 \mathrm{~Hz}, 3 \mathrm{H}, \mathrm{CH}_{3}\right), 4.29$ (q, $\left.J=7 \mathrm{~Hz}, 2 \mathrm{H}, \mathrm{CH}_{2}\right), 7.16-7.98(\mathrm{~m}, 19 \mathrm{H}, \operatorname{ArH}), 10.55(\mathrm{~s}, 1 \mathrm{H}, \mathrm{NH})$, 11.73 (s, 1H, NH). MS m/z (\%) $530\left(\mathrm{M}^{+}, 7\right), 366$ (15), 354 (54), 325 (14), 249 (18), 234 (16), 221 (19), 206 (11), 182 (29), 165 (35), 138 (8), 105 (73), 77 (100). Anal. Calcd. for $\mathrm{C}_{32} \mathrm{H}_{26} \mathrm{~N}_{4} \mathrm{O}_{4}$ (530.57): C, 72.44; H, 4.94; N, 10.56. Found: C, 72.18; $\mathrm{H}, 4.76 ; \mathrm{N}, 10.50 \%$.

Ethyl (1H-Perimidin-2-yl)-[(4-methoxyphenyl)-hydrazono]-acetate (10a) 
Brown solid, (88\% yield), mp 192-194 을 IR (KBr) $v_{\max } 3429,3112(2 \mathrm{NH}), 1740(\mathrm{C}=\mathrm{O}) \mathrm{cm}^{-1} ;{ }^{1} \mathrm{H}$ NMR $\left(\mathrm{DMSO}-\mathrm{d}_{6}\right) \delta 1.34(\mathrm{t}$, $\left.J=7 \mathrm{~Hz}, 3 \mathrm{H}, \mathrm{CH}_{3}\right), 3.72\left(\mathrm{~s}, 3 \mathrm{H}, \mathrm{OCH}_{3}\right), 4.31\left(\mathrm{q}, J=7 \mathrm{~Hz}, 2 \mathrm{H}, \mathrm{CH}_{2}\right), 6.69-7.46(\mathrm{~m}, 10 \mathrm{H}, \mathrm{ArH}), 10.80(\mathrm{~s}, 1 \mathrm{H}, \mathrm{NH}), 12.45(\mathrm{~s}$, $1 \mathrm{H}, \mathrm{NH})$. MS m/z (\%) $389\left(\mathrm{M}^{+}+1,13\right), 388(30), 135(26), 122(100), 107(36), 77$ (15). Anal. Calcd. for $\mathrm{C}_{22} \mathrm{H}_{20} \mathrm{~N}_{4} \mathrm{O}_{3}$ (388.42): C, 68.03; H, 5.19; N, 14.42. Found: C, 67.86; H, 4.95; N, 14.19\%.

\section{Ethyl (1H-Perimidin-2-yl)-[(4-methylphenyl)-hydrazono]-acetate (10b)}

Dark green solid, (90\% yield), mp 224-226 ${ }^{\circ} \mathrm{C}$ (Ethanol); IR (KBr) $\mathrm{V}_{\max } 3425,3145(2 \mathrm{NH}), 1739(\mathrm{C}=\mathrm{O}) \mathrm{cm}^{-1} ;{ }^{1} \mathrm{H} \mathrm{NMR}$ $\left(\right.$ DMSO-d $\left._{6}\right) \delta 1.25\left(\mathrm{t}, J=7 \mathrm{~Hz}, 3 \mathrm{H}, \mathrm{CH}_{3}\right), 2.32\left(\mathrm{~s}, 3 \mathrm{H}, \mathrm{CH}_{3}\right), 4.54\left(\mathrm{q}, J=7 \mathrm{~Hz}, 2 \mathrm{H}, \mathrm{CH}_{2}\right), 6.82-7.41(\mathrm{~m}, 10 \mathrm{H}, \mathrm{ArH}), 10.85(\mathrm{~s}$, $1 \mathrm{H}, \mathrm{NH}), 12.49(\mathrm{~s}, 1 \mathrm{H}, \mathrm{NH}) . \mathrm{MS} \mathrm{m} / \mathrm{z}(\%) 373\left(\mathrm{M}^{+}+1,20\right), 372\left(\mathrm{M}^{+}, 37\right), 371(23), 208(33), 255$ (30), 91 (100), $77(30)$. Anal. Calcd. for $\mathrm{C}_{22} \mathrm{H}_{20} \mathrm{~N}_{4} \mathrm{O}_{2}$ (372.42): C, 70.95; $\mathrm{H}, 5.41 ; \mathrm{N}, 15.04$. Found: $\mathrm{C}, 70.84 ; \mathrm{H}, 5.25 ; \mathrm{N}, 15.18 \%$.

\section{Ethyl (1H-Perimidin-2-yl)-[(3-methylphenyl)-hydrazono]-acetate (10c)}

Brown solid, (79\% yield), mp 178-180 ํ (Ethanol); IR (KBr) $v_{\max } 3411,3210(2 \mathrm{NH}), 1739(\mathrm{C}=\mathrm{O}) \mathrm{cm}^{-1} ; \delta 1.31(\mathrm{t}, \mathrm{J}=7 \mathrm{~Hz}$, $\left.3 \mathrm{H}, \mathrm{CH}_{3}\right), 2.25\left(\mathrm{~s}, 3 \mathrm{H}, \mathrm{CH}_{3}\right), 4.40\left(\mathrm{q}, J=7 \mathrm{~Hz}, 2 \mathrm{H}, \mathrm{CH}_{2}\right), 7.05-7.59(\mathrm{~m}, 10 \mathrm{H}, \mathrm{ArH}), 10.39(\mathrm{~s}, 1 \mathrm{H}, \mathrm{NH}), 11.98(\mathrm{~s}, 1 \mathrm{H}, \mathrm{NH})$. MS m/z (\%) $373\left(\mathrm{M}^{+}+1,3\right), 372\left(\mathrm{M}^{+}, 11\right), 273$ (100), 208 (39), 181 (47), 79 (15), 77 (29). Anal. Calcd. for $\mathrm{C}_{22} \mathrm{H}_{20} \mathrm{~N}_{4} \mathrm{O}_{2}$ (372.42): C, 70.95; $\mathrm{H}, 5.41 ; \mathrm{N}, 15.04$. Found: C, $70.90 \mathrm{H}, 5.19 ; \mathrm{N}, 15.07 \%$.

\section{Ethyl (1H-Perimidin-2-yl)-(phenylhydrazono)-acetate (10d)}

Brown solid, (82\% yield), mp 162-164 으 (Ethanol); IR (KBr) $v_{\max } 3415,3100(2 \mathrm{NH}), 1747(\mathrm{C}=\mathrm{O}) \mathrm{cm}^{-1} ;{ }^{1} \mathrm{H}$ NMR (DMSO $\left.\mathrm{d}_{6}\right) \delta 1.33\left(\mathrm{t}, J=7 \mathrm{~Hz}, 3 \mathrm{H}, \mathrm{CH}_{3}\right), 4.37\left(\mathrm{q}, J=7 \mathrm{~Hz}, 2 \mathrm{H}, \mathrm{CH}_{2}\right), 6.95-7.73(\mathrm{~m}, 11 \mathrm{H}, \mathrm{ArH}), 11.30(\mathrm{~s}, 1 \mathrm{H}, \mathrm{NH}), 12.46(\mathrm{~s}, 1 \mathrm{H}$, $\mathrm{NH})$. MS m/z (\%) $359\left(\mathrm{M}^{+}+1,15\right), 358\left(\mathrm{M}^{+}, 50\right), 194(25), 193(100), 105$ (35), 77 (70). Anal. Calcd. for $\mathrm{C}_{21} \mathrm{H}_{18} \mathrm{~N}_{4} \mathrm{O}_{2}$ (358.39): C, 70.38; H, 5.06; N, 15.63. Found: C, 70.17; H, 5.20; N, 15.46\%.

\section{Ethyl (1H-Perimidin-2-yl)-[(4-chlorophenyl)-hydrazono]-acetate (10e)}

Raddish brown solid (72\% yield), mp 180-182 으 (Ethanol/Dioxane); IR (KBr) $v_{\max } 3425,3215(2 \mathrm{NH}), 1739(\mathrm{C}=\mathrm{O}) \mathrm{cm}^{-1}$; MS m/z (\%) $393\left(\mathrm{M}^{+}+1,11\right), 392\left(\mathrm{M}^{+}, 38\right), 346(25), 222$ (64), 221 (46), 193 (100), 77 (20), 76 (11) Anal. Calcd. for $\mathrm{C}_{21} \mathrm{H}_{17} \mathrm{CIN}_{4} \mathrm{O}_{2}$ (392.84): C, 64.21; $\mathrm{H}, 4.36 ; \mathrm{N}, 14.26$. Found: C, 64.05; $\mathrm{H}, 4.19 ; \mathrm{N}, 14.04 \%$.

\section{Ethyl (1H-Perimidin-2-yl)-[(3-nitrophenyl)-hydrazono]-acetate (10f)}

Brick red solid (72\% yield), mp 208-210 ${ }^{\circ} \mathrm{C}$ (Ethanol/Dioxane); IR (KBr) $\mathrm{V}_{\max } 3421,3254(2 \mathrm{NH}), 1725(\mathrm{C}=\mathrm{O}) \mathrm{cm}^{-1} ;{ }^{1} \mathrm{H} \mathrm{NMR}$ (DMSO-d $\left.\mathrm{d}_{6}\right) \delta 1.32\left(\mathrm{t}, J=7 \mathrm{~Hz}, 3 \mathrm{H}, \mathrm{CH}_{3}\right), 4.30$ (q, $\left.J=7 \mathrm{~Hz}, 2 \mathrm{H}, \mathrm{CH}_{2}\right), 7.21-7.98(\mathrm{~m}, 10 \mathrm{H}, \mathrm{ArH}), 11.12(\mathrm{~s}, 1 \mathrm{H}, \mathrm{NH}), 12.49(\mathrm{~s}$, $1 \mathrm{H}, \mathrm{NH}) . \mathrm{MS} \mathrm{m} / \mathrm{z}(\%) 404\left(\mathrm{M}^{+}+1,15\right), 403\left(\mathrm{M}^{+}, 35\right), 402$ (19), $373(13), 191(56), 79(17), 65(100), 57$ (25), $56(35)$. Anal. Calcd. for $\mathrm{C}_{21} \mathrm{H}_{17} \mathrm{~N}_{5} \mathrm{O}_{4}$ (403.39): C, 62.53; $\mathrm{H}, 4.25 ; \mathrm{N}, 17.36$. Found: C, 62.34; $\mathrm{H}, 4.48 ; \mathrm{N}, 17.18 \%$

\section{Ethyl (1H-Perimidin-2-yl)-[(4-nitrophenyl)-hydrazono]-acetate (10g)}

Dark brown solid, (78\% yield), mp 204-206 ${ }^{\circ} \mathrm{C}$ (Ethanol/Dioxane); IR (KBr) $v_{\max } 3435,3190(2 \mathrm{NH}), 1739,(\mathrm{C}=\mathrm{O}) \mathrm{cm}{ }^{-1} ;{ }^{1} \mathrm{H}$ NMR (DMSO-d $\left.\mathrm{d}_{6}\right) \delta 1.31\left(\mathrm{t}, J=7 \mathrm{~Hz}, 3 \mathrm{H}, \mathrm{CH}_{3}\right), 4.32\left(\mathrm{q}, J=7 \mathrm{~Hz}, 2 \mathrm{H}, \mathrm{CH}_{2}\right), 7.19-8.27(\mathrm{~m}, 10 \mathrm{H}, \mathrm{ArH}), 11.58(\mathrm{~s}, 1 \mathrm{H}, \mathrm{NH})$, $12.21(\mathrm{~s}, 1 \mathrm{H}, \mathrm{NH}) . \quad \mathrm{MS} \mathrm{m} / \mathrm{z}(\%) 403\left(\mathrm{M}^{+}+1,15\right), 402\left(\mathrm{M}^{+}, 39\right), 194$ (24), $193(100), 77$ (10), 65 (37). Anal. Calcd. for $\mathrm{C}_{21} \mathrm{H}_{17} \mathrm{~N}_{5} \mathrm{O}_{4}$ (403.39): C, 62.53; H, 4.25; N, 17.36. Found: C, 62.49; H, 4.16; N, 17.30\%.

\section{Ethyl (1H-Perimidin-2-yl)-[(4-acetylphenyl)-hydrazono]-acetate (10h)}

Dark green solid, (81\% yield), mp 168-170 ${ }^{\circ} \mathrm{C}$ (Ethanol/Dioxane); IR $(\mathrm{KBr}) \mathrm{v}_{\max } 3418,3297(2 \mathrm{NH}), 1732,1686(2 \mathrm{C}=\mathrm{O}) \mathrm{cm}$ 1; ${ }^{1} \mathrm{H}$ NMR (DMSO-d $) \delta 1.32\left(\mathrm{t}, \mathrm{J}=7 \mathrm{~Hz}, 3 \mathrm{H}, \mathrm{CH}_{3}\right), 2.37\left(\mathrm{~s}, 3 \mathrm{H}, \mathrm{OCH}_{3}\right), 4.33\left(\mathrm{q}, \mathrm{J}=7 \mathrm{~Hz}, 2 \mathrm{H}, \mathrm{CH}_{2}\right), 6.63-8.01(\mathrm{~m}, 10 \mathrm{H}$, ArH), 11.58 (s, 1H, NH), 12.09 (s, 1H, NH). MS m/z (\%) 401 (M+1, 11), 400 (54), 399 (36), 193 (100), 192 (76), 180 (20), 78 (32), 77 (31), 65 (21). Anal. Calcd. for $\mathrm{C}_{23} \mathrm{H}_{20} \mathrm{~N}_{4} \mathrm{O}_{3}$ (400.43): C, 68.99; H, 5.03; N, 13.99. Found: C, 68.82; H, 5.16; N, $13.78 \%$.

\section{Ethyl (1H-Perimidin-2-yl)-[(4-ethoxycarbonylphenyl)-hydrazono]-acetate (10i)}

Dark red solid, (80\% yield), mp 166-168 ${ }^{\circ} \mathrm{C}$ (Ethanol/Dioxane); IR (KBr) $v_{\max } 3423,3118(2 \mathrm{NH}), 1739,1712(2 \mathrm{C}=\mathrm{O}) \mathrm{cm}^{-1}$; MS m/z (\%) $431\left(\mathrm{M}^{+}+1,17.4\right), 430\left(\mathrm{M}^{+}, 40\right), 429(26), 194(36), 193(100), 192(62), 78(28), 77$ (34). Anal. Calcd. for $\mathrm{C}_{24} \mathrm{H}_{22} \mathrm{~N}_{4} \mathrm{O}_{4}(430.46): \mathrm{C}, 66.97 ; \mathrm{H}, 5.15 ; \mathrm{N}, 13.02$. Found: $\mathrm{C}, 66.82 ; \mathrm{H}, 5.02 ; \mathrm{N}, 12.89 \%$.

\section{Agar diffusion well method to determine the antimicrobial activity:}

The microorganism inoculums were uniformly spread using sterile cotton swab on a sterile petri dish malt extract agar (for fungi) and nutrient agar (for bacteria). One hundred ML of each sample was added to each well (6 mm diameter holes cut in the agar gel, $20 \mathrm{~mm}$ agar from one another). The systems were incubated for $24-48 \mathrm{~h}$ at $37 \stackrel{\circ}{\circ} \mathrm{C}$ (for bacteria) and at 28 ${ }^{\circ} \mathrm{C}$ (for fungi). After incubation, the micro-organisms growth was observed. Inhibition of the bacterial and fungal growth were measured in $\mathrm{mm}$. Tests were performed in triplicate [27].

\section{Results and discussion}

The starting ketene aminal $\mathbf{3}$ was prepared by reaction of the thione $\mathbf{1}$ with phenacyl bromide in aqueous sodium hydroxide to give 2-[(benzoylmethyl)thio]imidazolin-4-one 2, then, thermal heating of compound 2 in diphenyl ether at 200 $21{ }^{\circ} \mathrm{C}$ afforded the ketene aminal 3 in good yield via extrusion of sulfur (Scheme 1). It is worth mentioning that the structure of compound $\mathbf{3}$ is consistent with the recent article [25] which reporting the synthesis of ketene aminal $\mathbf{3}$ via the Eschenmoser coupling reaction. 
<smiles>O=C1NC(=S)NC1(c1ccccc1)c1ccccc1</smiles><smiles>CC(=O)OCC1=NC(c2ccccc2)(c2ccccc2)C(=O)N1C</smiles><smiles>C#CC(=O)c1ccccc1</smiles><smiles>COCCN1C(=O)C(c2ccccc2)(c2ccccc2)N=C1CC(=O)c1ccccc1</smiles>

Scheme 1

Coupling of compound 3 with diazotized aniline and its derivatives 4a-j in aqueous ethanol in the presence of sodium hydroxide afforded the respective arylazo derivatives 5a-j (Scheme 2). The mass spectra of the latter products revealed the molecular ion peaks at the expected $\mathrm{m} / \mathrm{z}$ values and their elemental analysis data are consistent with their assigned structure. As shown in Scheme 2, compounds $\mathbf{5}$ may have one or more of six possible tautomeric structures A-F. Of these forms, structure $5 \mathrm{~A}$ seems to be the forms of choice as they are consistent with their electronic absorption of compounds 5. For example, like typical hydrazones [28,29], the electronic absorption spectra of $\mathbf{5}$ in dioxane revealed in each case two characteristic absorption bands in the regions $\lambda_{\max } 393-331$ and 334-229 $\mathrm{nm}$ (Table 1). Furthermore, the electronic spectrum of $\mathbf{5 d}$, taken as typical example of the series studied, was recorded in solvents of different polarities. The spectra obtained showed little, if any, shift (Table 1) and the small shifts found in $\boldsymbol{\lambda}_{\max }$ of $\mathbf{5} \mathbf{d}$ in different solvents are due to solutesolvent interaction. In agreement with this conclusion is the observation that the spectra of arylhydrazones derived from the reaction of quinones with $\mathrm{N}$-alkyl- $\mathrm{N}$-phenylhydrazine, unlike those of $O$ - and $p$-hydroxyazo compounds, are largely independent of the solvent polarity [29]. This finding excludes the other tautomeric forms B-F (Scheme 2). Other conclusive evidence for elucidation of the actual tautomeric structure 5A was obtained from the X-ray crystallographic analysis of compound $\mathbf{5 f}$ which illustrated in Figure 1. The selected bond lengths and bond angles of structure 5Af are depicted in Table 2 [24].

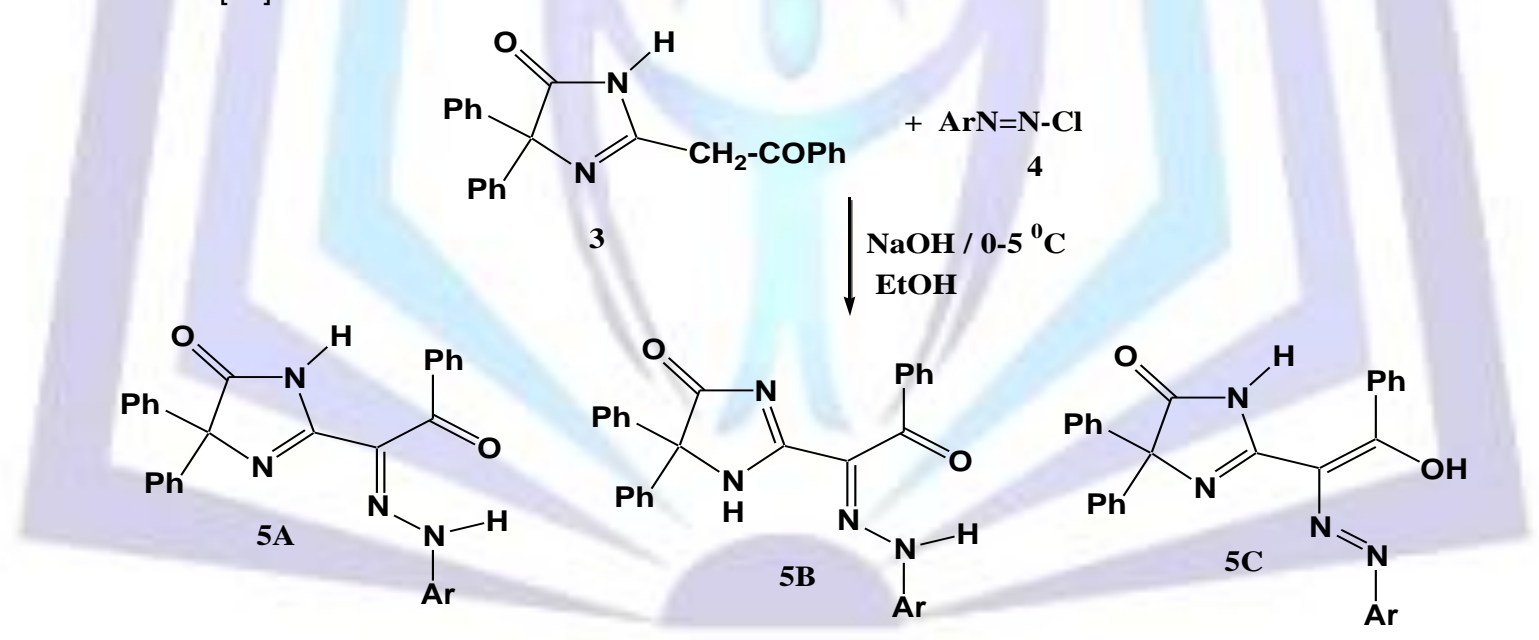<smiles>O=C(/C(N=NC1CCCCC1)=C1\NC(=O)C(c2ccccc2)(c2ccccc2)N1)c1ccccc1</smiles><smiles>O=C(/C(N=NC1CCCCC1)=C1/N=C(O)C(c2ccccc2)(c2ccccc2)N1)c1ccccc1</smiles><smiles>OC(=NN=NC1CCCCC1)C1=NC(c2ccccc2)(c2ccccc2)C(O)=N1</smiles>

$\mathrm{Ar}=\mathrm{XC}_{6} \mathrm{H}_{4}$

$\mathrm{X}: \mathrm{a}, \mathrm{4-MeO}$; b, 4-Me; c, 3-Me; d, H; e, 3-Cl; f, 4-Cl; g, 3- $\mathrm{NO}_{2}$; h, 4-NO i, 4-COMe; j, 4-COOEt

\section{Scheme 2}


Table 1. UV Spectral data of compounds 5a-j in dioxane

\begin{tabular}{ll}
\hline Compd. no. & $\lambda \max (\log \mathbf{\varepsilon}) \mathbf{n m}$ \\
\hline $\mathbf{5 a}$ & $332(3.24), 300(3.52)$ \\
$\mathbf{5 b}$ & $332(4.03), 229(5.11)$ \\
$\mathbf{5 c}$ & $331(4.20), 229(5.0)$ \\
$\mathbf{5 \mathbf { d } ^ { \star }}$ & $333(4.70), 255(3.28)$ \\
$\mathbf{5 e}$ & $376(4.48), 249(4.16)$ \\
$\mathbf{5 f}$ & $384(3.51), 333(3.62)$ \\
$\mathbf{5 g}$ & $382(4.15), 229(3.66)$ \\
$\mathbf{5 h}$ & $393(3.49), 333(3.67)$ \\
$\mathbf{5 i}$ & $388(3.19), 334(3.90)$ \\
$\mathbf{5 j}$ & $384(3.67), 334(3.89)$
\end{tabular}

$\left.{ }^{*}\right)$ Solvent $\lambda_{\max }(\log \varepsilon)$ : acetone: 333 (4.87), 254 (3.61); acetic acid: 339 (4.56), 238 (3.21); cyclohexane: 309 (3.21), 238 (4.05); ethanol 335 (4.85), 246 (4.45)

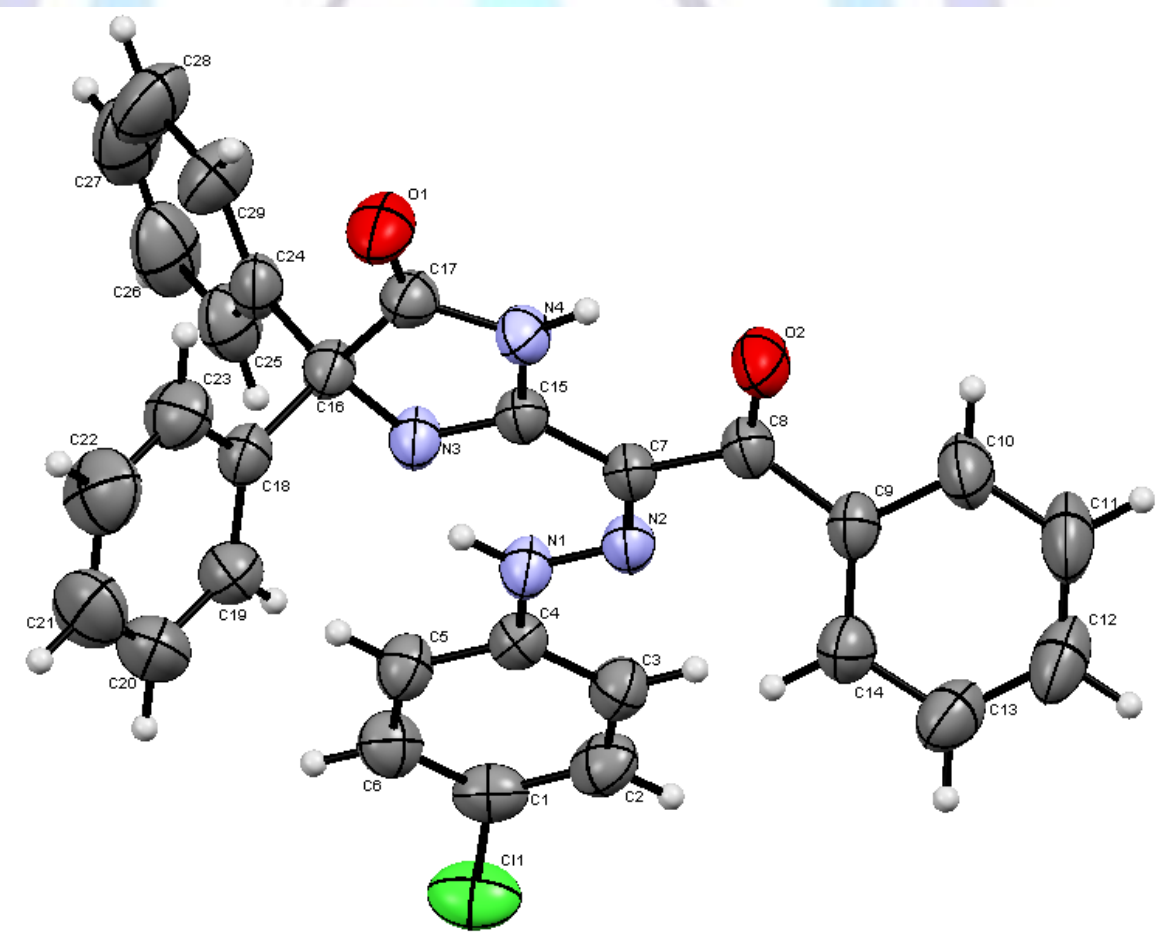

Figure 1. ORTEP crystal structure of compound 5Af. 
Table 2

Selected bond lengths and bond angles in the ORTEP figure of compound $\mathbf{5} f$ in the crystal. The crystallographic numbering does not reflect systematic numbering.

\begin{tabular}{lll}
\hline Bond length, $\ddot{A}$ & Bond length, $\AA$ & Angle $(\omega)$ \\
\hline N1-N2, 1.3061 & N4-C17, 1.3604 & C15-C7-C8, 120.22 \\
N2-C7, 1.3217 & C15-N4, 1.3797 & N2-N1-C4, 122.19 \\
C4-N1, 1.3973 & N3-C16, 1.4654 & N2-C7-C8, 116.74 \\
O2-C8, 1.2312 & C15-N3, 1.2939 & N3-C15-N4, 113.58 \\
C7-C8, 1.4759 & N1-H1, 0.86 & C15-N3-C16, 108.04 \\
\hline
\end{tabular}

In conjunction to our interest in the synthesis of new bioactive hydrazone derivatives [7-15], herein we reported the coupling reaction of the enaminone 7 with diazotized anilines giving the respective arylazo derivatives 10a-i (Scheme 3). Enaminone 7 was prepared by condensation of the ketene aminal 6 [26] with DMF-DMA in dry toluene under reflux. The structure of the enaminone 7 was established on the basis of spectral data and elemental analyses. For example, its ${ }^{1} \mathrm{H}$ NMR spectrum exhibited the characteristic signals for the enaminone moiety at $\delta 8.72,2.90$ and $2.85 \mathrm{ppm}$ assigned for the olefinic $=\mathrm{CH}$ and the two methyl protons of $-\mathrm{N}\left(\mathrm{CH}_{3}\right)_{2}$ group in addition to the expected signals assigned for $\mathrm{NH}$, aromatic and ester protons. Coupling of the latter enaminone 7 with diazotized anilines gives the respective arylazo derivatives 10a-i. On the basis of elemental analyses, IR, ${ }^{1} \mathrm{H}$ NMR, and UV spectra (see Experimental), the isolated products were assigned structure 10. The formation of the products $(\mathbf{1 0 a}-\mathbf{i})$ is assumed to take place via Japp-Klingemann reaction with elimination of dimethylformamide from the intermediate $\mathbf{9}$ to afford the product $\mathbf{7}$ as shown in Scheme 3. In addition, the assigned structure for the products $\mathbf{1 0}$ was further confirmed by an alternative method for their synthesis. Thus, reaction of compound 6 with arendiazonium salts in ethanolic sodium hydroxide at $0-5 \stackrel{\circ}{\circ} \mathrm{C}$ afforded products which are typical in all respects (mp., mixed mp. and IR) with products 10 .

Compounds 10 can exist in one or more of the three tautomeric forms 10A-C (Scheme 3 ). Of these three forms, the tautomeric form 10C seems to be the actual form for the studied compounds as it is consistent with their electronic absorption spectra, IR and ${ }^{1} \mathrm{H}$ NMR spectra. For example, like typical azo-compounds [15] the electronic absorption spectra of 10a-i in dioxane revealed, in each case two characteristic absorption bands in the regions $\lambda_{\max } 537-501$ and 396-362 nm (Table 3) and the electronic spectra of compound 10d, taken as a typical example of the series prepared, in different solvents exhibited little, if there is any, solvent dependence (Table 3). Also, their IR spectra revealed in each case two NH and carbonyl absorption bands in the regions 3435-3411, 3297-3100 and 1747-1725 $\mathrm{cm}^{-1}$, respectively. The ${ }^{1} \mathrm{H}$ NMR spectra are characterized by the two singlet signals assignable to two NH protons at $\delta 10.80-11.58$ and $11.98-$ $12.49 \mathrm{ppm}$. These findings indicated that the isolated products exist in the tautomiric form 10C. 

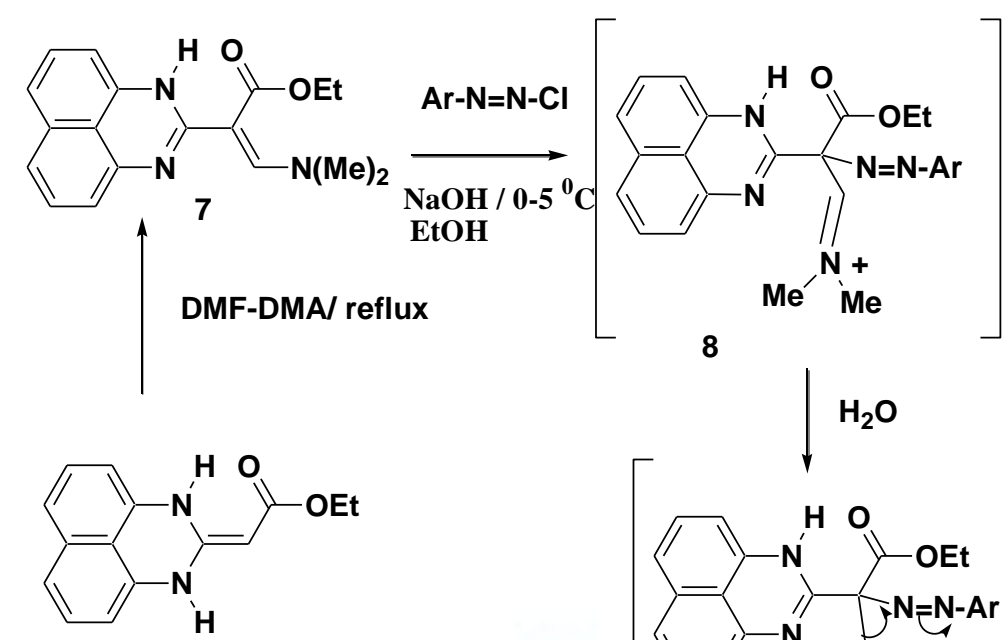

6
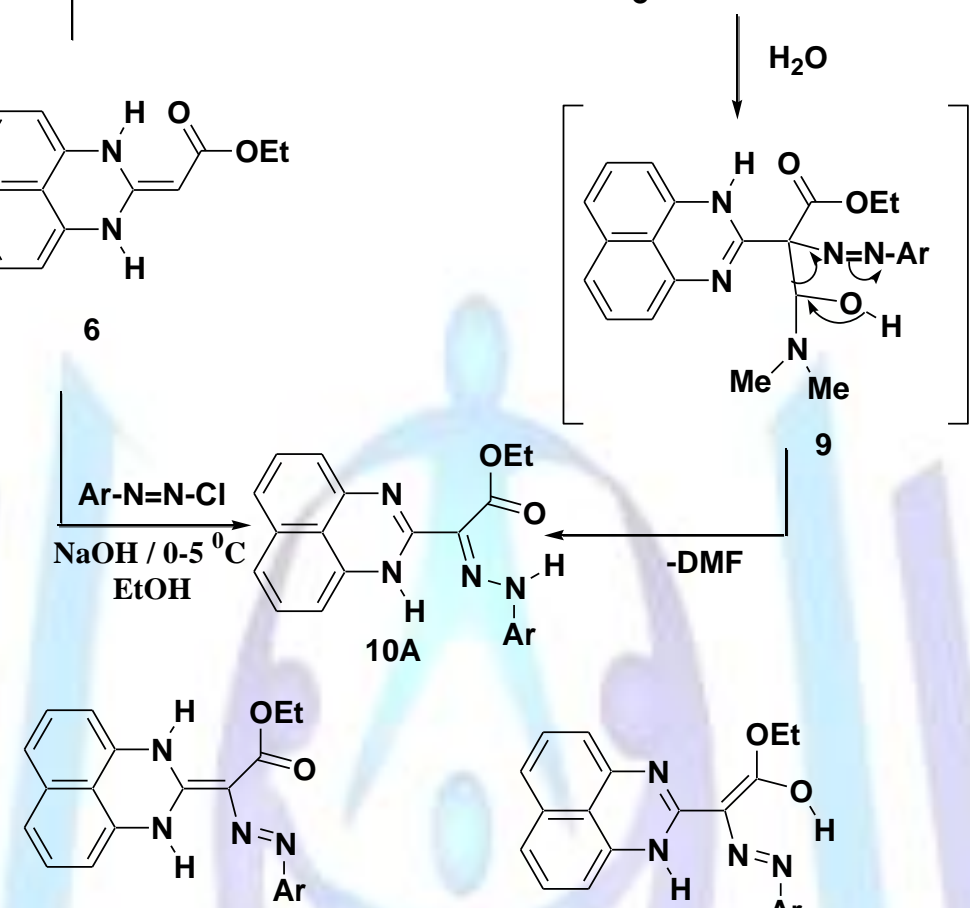

$10 \mathrm{C}$

$\mathrm{Ar}=\mathrm{XC}_{6} \mathrm{H}_{4}$

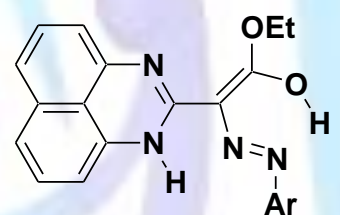

$\mathrm{X:} \mathrm{a,} \mathrm{4-MeO;} \mathrm{b,} \mathrm{4-Me;} \mathrm{c,} \mathrm{3-Me;} \mathrm{d,} \mathrm{H;} \mathrm{e,} \mathrm{4-Cl;} \mathrm{f,} \mathrm{3-} \mathrm{NO}_{2}$; $\mathrm{g} \mathrm{4- \textrm {NO } _ { 2 }}$

h, 4-COMe; i, 4-COOEt

Scheme 3. Synthesis of compounds 10a-i

Table 3. UV Spectral data of compounds 10a-i in dioxane

\begin{tabular}{ll}
\hline Compd. no. & $\lambda_{\max }(\log \varepsilon) \mathrm{nm}$ \\
\hline $\mathbf{1 0 a}$ & $501(4.19), 395(3.97)$ \\
10b & $503(3.96), 383(4.54)$ \\
10c & $501(4.14), 381(3.67)$ \\
10d* & $505(4.09), 362(3.48)$ \\
10e & $521(4.86), 383(3.94)$ \\
10f & $506(4.97), 377(4.67)$ \\
10g & $515(4.84), 363(4.50)$ \\
10h & $537(4.09), 396(4.31)$ \\
10i & $523(4.45), 386(4.18)$
\end{tabular}

*) Solvent $\lambda_{\max }(\log \varepsilon)$ : acetone: 508 (3.05), 376 (3.68); cyclohexane: 500 (3.09), 375 (3.11); ethanol: 502 (3.29), 359 (3.10); DMF: 502 (3.11), 359 (4.31). 


\section{Biological Screening}

\section{Anti-microbial activity}

In vitro anti-microbial screening of the tested compounds 3,5 and 10 was carried out using four fungal strains, including Aspergillus fumigatus ( $A F$, Syncephalastrum racemosum (SR) Geotricum candidum (GC) and Candida albicans (CA) and four bacteria species, including Gram positive bacteria, straphylococcus Pneumonia (SP) and Bacillus stubtilis (BS), Gram negative bacteria, Pseudomonas aeruginosa $(P A)$ and Escherichia coli $(E C)$. The reference drugs used for comparison are commonly applied antibiotics such as Amphotericin B, Ampicillin and Gentamicin (See Table 4). Preliminary antimicrobial activity for the tested compounds $\mathbf{3}, \mathbf{5}$ and $\mathbf{1 0}$ indicate that compound $\mathbf{3}$ showed weak to mild activity aganist all used microorganisms, except fungus $S R$ and Gram negative bacteria PA. Among compounds $\mathbf{5}$, the compound 5 a has high potency aganist most of the tested fungi and bacteria species.

On the other hand, the results obtained for products $\mathbf{1 0}$ indicate that all these compounds have mild to zero activity ganist the used microorganisms. Compound $10 \mathrm{~g}$ has high potency aganist fungus $A F$ and Gram postive bacteria $G C, S A, B S$ and Gram negative bacteria $E C$, whereas compound 10a has mild activity aganist fungi $A F$ and $G C$ and Gram postive bacteria $S A$ and $B S$. Moreover, the results depicted in Table 4 indicate that compounds 10f and 10i exhibited no activity against fungi $P I$ and $C A$ and Gram negative bacteria $P A$ and they have high to mild activity against fungi species $A F$ and $G C$ and Gram postive bacteria $S A, B S$ and Gram negative bacteria $E C$. Compounds 10b, 10c and 10e have no fungal and bacteria activity.

Table 4. Preliminary anti-microbial activity for tested compounds 3, 5 and $\mathbf{1 0}$

\begin{tabular}{|c|c|c|c|c|c|c|c|c|}
\hline Compd & Fungi & & & & $\begin{array}{l}\text { Gram } \\
\text { bacteria }\end{array}$ & positive & $\begin{array}{l}\text { Gram } \\
\text { bacteria }\end{array}$ & negative \\
\hline No. & $A F$ & $S R$ & $G C$ & $C A$ & $S P$ & $B S$ & $P A$ & $E C$ \\
\hline 3 & $\begin{array}{l}11.2 \\
( \pm 0.44)\end{array}$ & N.A. & $\begin{array}{l}12.9 \\
( \pm 0.44)\end{array}$ & $\begin{array}{l}10.4 \\
( \pm 0.58)\end{array}$ & $\begin{array}{l}12.6 \\
( \pm 0.27)\end{array}$ & $\begin{array}{l}13.9 \\
( \pm 0.14)\end{array}$ & N.A. & N.A. \\
\hline $5 a$ & $\begin{array}{l}20.3 \\
( \pm 0.44)\end{array}$ & N.A. & $\begin{array}{l}22.4 \\
( \pm 0.58)\end{array}$ & $\begin{array}{l}19.6 \\
( \pm 0.37\end{array}$ & $\begin{array}{l}20.2 \\
( \pm 0.44)\end{array}$ & $\begin{array}{l}22.3 \\
( \pm 0.58)\end{array}$ & $\begin{array}{l}13.8 \\
( \pm 0.37)\end{array}$ & $\begin{array}{l}16.8 \\
( \pm 0.58)\end{array}$ \\
\hline $5 b$ & $\begin{array}{l}10.2 \\
( \pm 0.58)\end{array}$ & N.A. & $\begin{array}{l}12.6 \\
( \pm 0.44)\end{array}$ & $\begin{array}{l}9.3 \\
( \pm 0.63)\end{array}$ & $\begin{array}{l}11.4 \\
( \pm 0.44)\end{array}$ & $\begin{array}{l}12.3 \\
( \pm 0.25)\end{array}$ & N.A. & N.A. \\
\hline $5 c$ & $\begin{array}{l}16.3 \\
( \pm 0.44)\end{array}$ & N.A. & $\begin{array}{l}17.2 \\
( \pm 0.25)\end{array}$ & $\begin{array}{l}15.3 \\
( \pm 0.48)\end{array}$ & $\begin{array}{l}17.8 \\
( \pm 0.67)\end{array}$ & $\begin{array}{l}19.2 \\
( \pm 0.44)\end{array}$ & N.A. & $\begin{array}{l}13.4 \\
( \pm 0.58)\end{array}$ \\
\hline $5 d$ & $\begin{array}{l}11.6 \\
( \pm 0.44)\end{array}$ & N.A. & $\begin{array}{l}12.7 \\
( \pm 0.58)\end{array}$ & $\begin{array}{l}13.2 \\
( \pm 0.63)\end{array}$ & $\begin{array}{l}15.6 \\
( \pm 0.44)\end{array}$ & $\begin{array}{l}15.9 \\
( \pm 0.44)\end{array}$ & N.A. & $\begin{array}{l}12.6 \\
( \pm 0.58)\end{array}$ \\
\hline $5 e$ & $\begin{array}{l}18.3 \\
( \pm 0.44)\end{array}$ & N.A. & $\begin{array}{l}19.2 \\
( \pm 0.58)\end{array}$ & $\begin{array}{l}18.4 \\
( \pm 0.44)\end{array}$ & $\begin{array}{l}18.4 \\
( \pm 0.37)\end{array}$ & $\begin{array}{l}20.2 \\
( \pm 0.37)\end{array}$ & N.A. & $\begin{array}{l}15.3 \\
( \pm 0.44)\end{array}$ \\
\hline $5 f$ & $\begin{array}{l}17.3 \\
( \pm 0.58)\end{array}$ & N.A. & $\begin{array}{l}18.3 \\
( \pm 0.44)\end{array}$ & $\begin{array}{l}16.0 \\
( \pm 0.37)\end{array}$ & $\begin{array}{l}16.7 \\
( \pm 0.37)\end{array}$ & $\begin{array}{l}19.3 \\
( \pm 0.44)\end{array}$ & N.A. & $\begin{array}{l}14.3 \\
( \pm 0.58)\end{array}$ \\
\hline $5 h$ & $\begin{array}{l}14.2 \\
( \pm 0.58)\end{array}$ & N.A. & $\begin{array}{l}15.7 \\
( \pm 0.58)\end{array}$ & $\begin{array}{l}13.1 \\
( \pm 0.37)\end{array}$ & $\begin{array}{l}15.6 \\
( \pm 0.44)\end{array}$ & $\begin{array}{l}17.2 \\
( \pm 0.58)\end{array}$ & N.A. & $\begin{array}{l}15.3 \\
( \pm 0.44)\end{array}$ \\
\hline $10 a$ & $\begin{array}{l}10.3 \\
( \pm 0.58)\end{array}$ & N.A. & N.A. & $\begin{array}{l}12.4 \\
( \pm 0.63)\end{array}$ & $\begin{array}{l}13.6 \\
( \pm 0.58)\end{array}$ & $\begin{array}{l}14.9 \\
( \pm 0.58)\end{array}$ & N.A. & N.A. \\
\hline $10 b$ & N.A & N.A & N.A. & N.A & N.A & N.A & N.A. & N.A \\
\hline $10 c$ & N.A & N.A & N.A. & N.A & N.A & N.A & N.A. & N.A \\
\hline $10 d$ & N.A & N.A & N.A. & N.A & $\begin{array}{l}13.3 \\
( \pm 0.58)\end{array}$ & $\begin{array}{l}12.6 \\
( \pm 0.44)\end{array}$ & N.A. & N.A. \\
\hline
\end{tabular}




$\begin{array}{lllllllll}10 \mathrm{e} & \text { N.A } & \text { N.A } & \text { N.A. } & \text { N.A } & \text { N.A } & \text { N.A } & \text { N.A. } & \text { N.A } \\ \begin{array}{l}\text { Amphotericin } \\ \text { B }\end{array} & 23.7 & 19.7 & 28.7 & 25.4 & \text { N.A. } & \text { N.A. } & \text { N.A. } & \text { N.A. } \\ \text { Ampicillin } & \begin{array}{l}( \pm 0.10) \\ \text { N.A. }\end{array} & \text { N.A. } & \text { N.A. } & \text { N.A. } & 23.8 & 32.4 & \text { N.A. } & \text { N.A. } \\ \text { Gentamicin } & \text { N.A. } & \text { N.A. } & \text { N.A. } & \text { N.A. } & \text { N.A. } & \text { N.A. } & 17.3 & 19.9 \\ & & & & & & & ( \pm 0.1) & ( \pm 0.30)\end{array}$

Table 4. Preliminary anti-microbial activity for tested compounds

\begin{tabular}{|c|c|c|c|c|c|c|c|c|}
\hline Compd & Fungi & & & & $\begin{array}{l}\text { Gram } \\
\text { bacteria }\end{array}$ & positive & $\begin{array}{l}\text { Gram } \\
\text { bacteria }\end{array}$ & negative \\
\hline No. & $A F$ & SR & $G C$ & $C A$ & $S P$ & $B S$ & $P A$ & $E C$ \\
\hline $10 f$ & $\begin{array}{l}14.9 \\
( \pm 0.58)\end{array}$ & N.A. & N.A. & $\begin{array}{l}17.3 \\
( \pm 0.58)\end{array}$ & $\begin{array}{l}16.9 \\
( \pm 0.63)\end{array}$ & $\begin{array}{l}19.3 \\
( \pm 0.67)\end{array}$ & N.A. & $\begin{array}{l}11.3 \\
( \pm 0.44)\end{array}$ \\
\hline $10 \mathrm{~g}$ & $\begin{array}{l}17.3 \\
( \pm 0.58)\end{array}$ & N.A. & N.A. & $\begin{array}{l}22.4 \\
( \pm 0.58)\end{array}$ & $\begin{array}{l}19.6 \\
( \pm 0.58)\end{array}$ & $\begin{array}{l}22.5 \\
( \pm 0.44)\end{array}$ & N.A. & $\begin{array}{l}14.6 \\
\pm 0.44\end{array}$ \\
\hline $10 i$ & $\begin{array}{l}16.9 \\
( \pm 0.15)\end{array}$ & N.A. & N.A. & $\begin{array}{l}19.9 \\
( \pm 0.26)\end{array}$ & $\begin{array}{l}18.1 \\
( \pm 0.44)\end{array}$ & $\begin{array}{l}20.9 \\
( \pm 0.58)\end{array}$ & N.A. & $\begin{array}{l}12.2 \\
( \pm 0.13)\end{array}$ \\
\hline $\begin{array}{l}\text { Amphotericin } \\
\text { B }\end{array}$ & $\begin{array}{l}23.7 \\
( \pm 0.10)\end{array}$ & $\begin{array}{l}19.7 \\
( \pm 0.2)\end{array}$ & $\begin{array}{l}28.7 \\
( \pm 0.20)\end{array}$ & $\begin{array}{l}25.4 \\
( \pm 0.1)\end{array}$ & N.A. & N.A. & N.A. & N.A. \\
\hline Ampicillin & N.A. & N.A. & N.A. & N.A. & $\begin{array}{l}23.8 \\
( \pm 0.2)\end{array}$ & $\begin{array}{l}32.4 \\
( \pm 0.30)\end{array}$ & N.A. & N.A. \\
\hline Gentamicin & N.A. & N.A. & N.A. & N.A. & N.A. & N.A. & $\begin{array}{l}17.3 \\
( \pm 0.1)\end{array}$ & $\begin{array}{l}19.9 \\
( \pm 0.30)\end{array}$ \\
\hline
\end{tabular}

\section{Conclusion}

In this paper we described an efficient and simple method for preparation of two new hydrazone series 5 and $\mathbf{1 0}$. The method summarized in coupling reaction of 2-benzoylmethylene-5,5-diphenyl-3,5-dihydroimidazol-4-one 3 and enaminone 7 with arenediazonium salts in ethanolic sodium hydroxide solution at low temperature $\left(0-5{ }^{\circ} \mathrm{C}\right)$. The electronic absorption spectra (UV/vis) together with the other spectral methods (IR, ${ }^{1} \mathrm{H}$ NMR, mass) indicated that products $\mathbf{5}$ exist in the tautomeric hydrazone form 5A. Further confirmation for the tautomeric form $\mathbf{5 A}$ was based on the X-ray crystallographic analysis which recorded for one typical example for series 5 . In a similar manner and based on electronic absorption spectra together with the data obtained from spectral (IR, ${ }^{1} \mathrm{H}$ NMR, mass) analyses of products 10 , it was found that the predominant tautomeric form is $10 \mathrm{c}$. In addition, the biological activity for products 5 and 10 were screened and the results obtained revealed that compounds 5 and $\mathbf{1 0} \mathrm{g}$ have promising potency against most the used fungal and bacteria species.

\section{REFERENCES}

[1] K. Takagi, A. Mizuno, H. Iwamoto, S. Kawashima, S. Nishida, T. Hashikawa, et al. Dyes Pigments, 26(1) (1994) 51-60.

[2] Y. M. ElKholy, S. A. Abd El-Hafiz, Pigment Resin Technol, 23(4) (1994) 3-5.

[3] A. S. Shawali, M. H.Abdelkader, F. M. A. Eltalbawy, Tetrahedron 58(14) (2002) 2875-2880.

[4] I. Se،ner, F. Karci, N. Ertan, E. Kilic, Dyes Pigments 70(2) (2006) 143-148.

[5] Ušc'umlic' GS, Mijin DZ, Valentic' NV, Vajs VV, Sus 'ic' BM. Substituent and solvent effects on the UV/Vis absorption spectra of 5-(4-substituted arylazo)-6-hydroxy-4-methyl-3-cyano-2-pyridones. Chem Phys Lett 
397(1-3) (2004) 148-153.

[6] M. M. M. Raposo, A. M. R. C. Sousa, A. M. C. Fonseca, G.Kirsch, Tetrahedron 61(34) (2005) 8249-8256.

[7] A. S. Shawali, T. A. Farghaly, Tetrahedron, 60(2004) 3051-3057.

[8] A. S. Shawali, M. A. N. Mosselhi, T. A. Farghaly, J. Chem. Res., (2007) 479-483.

[9] A. S. Shawali, S. M. Sherif, T. A. Farghaly, M. R. Shehata, M. A. A. Darwish, J. Chem. Res. (2007)44-47.

[10] A. S. Shawali, M. A. Mosselhi, F. M. A. Altablawy, T. A. Farghaly, N. M. Tawfik, Tetrahedron, 64(2008)5524-5530.

[11] T. A. Farghaly, Z. A. Abdallah, Arkivok, (xvii) (2008) 295-305.

[12] T. A. Farghaly, M. M. Abdalla, Bioorg. \& Med. Chem., 17(2009) 8012-8019.

[13] T. A. Farghaly, A. S. Shawali, J. Chem. research, 36(5) (2012) 296-299.

[14] T. A. Farghaly, M. M. Edrees, M. A. N. Mosselhi, Molecules, 17(2012) 8483-8493.

[15] T. A. Farghaly, H. K. Mahmoud, Arch. Pharm. Chem. Life Sci. 346 (2013) 392-402.

[16] K. C. Liu, Zhonghua Yaoxue Zazhi, 40 (1988)203-216.

[17] R. M. Claramunt, J. Dotor, J. Ann. Quim. 91(1995) 151-183.

[18] Undheim, K.; Benneche, C.; Comprehensive Heterocyclic Chemistry II.; Katritzky, A. R.; Rees, C. W.; Scriven, E. F. V. Eds., Pergamon, Oxford, 1986, Vol. 6, Chapter 2.

[19] D. Sharma, B. Narasimhan, P. Kumar, V. Judge, R. Narang, E. De Clercq, J. Balzarini, Eur. J. Med. Chem., 44 (2009) 2347-2353.

[20] K. C. S.Achar, K. M. Hosamani, H. R. Seetharamareddy, Eur. J. Med. Chem., 45 (2010) $2048-2054$.

[21] A. Puratchikodya, M. Doble, Bioorg. Med. Chem., 15 (2007) 1083-1090.

[22] Y.; Morita, S. Suzuki, K. Fukui, S. Nakazawa, H. Kitagawa, H. Kishida, H. Okamoto, A. Naito, A. Sekine, Y. Ohashi, M. Shiro, D. Sasaki, D. Shiomi, K. Sato, T. Takui, K. Nakasuji, Nat. Mat., 7 (2008)48-51.

[23] Y. Morita, K. Aoki, S. Nakazawa, K. Tamaki, S. Suzuki, A. Fuyuhiro, K. Yamamoto, D. Shiomi, A. Naito, T. Takui, K., Nakasuji, Angew. Chem. Int. Ed., 41 (2002) 1793-1796.

[24] All crystallographic data have been deposited at the Cambridge Crystallographic Data Centre as supplementary publication no. CCDC 900304 . Copies of the data can be obtained free of charge on application to CCDC, 12 Union Road, Cambridge CB2 1EZ, UK.

[25] S. Singh, J. M. Köhler, A. Schober, G. A. Groß. Beilstein J. Org. Chem. 7 (2011) 1164-1172.

[26] Paragamian, V.; Baker, M.B.; Puma, B.M.; Reale, J. J. Heterocycl. Chem., 5(1968) 591-597.

[27] J. A. Smania, F. D. Monache, E. F. A. Smania, R. S. Cuneo, Int. J. Med. Mushrooms, 1(1999) 325-330.

[28] A. S. Shawali, T. A. Farghaly, Tetrahedron, 65 (2009) 644-647.

[29] A. S. Shawali, Sherif, S. M.; Farghaly, T. A.; Shehata, M. R.; Darwish, M. A. A. J. Chem. Res. (2007)4447.

\section{Author' biography with Photo}

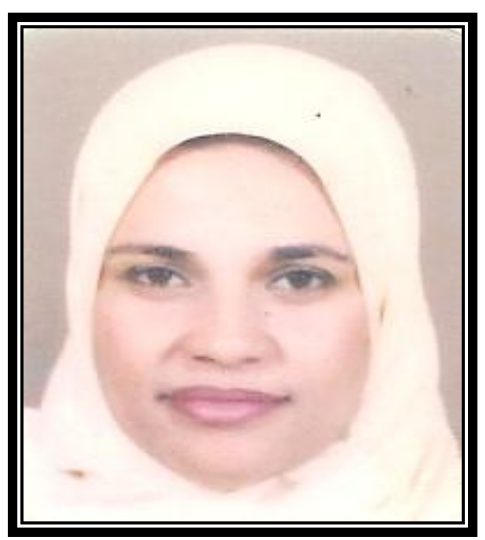

Thoraya Abd Elreheem Farghaly was born in Cairo, Egypt in 1974. She received her B.Sc. (1996); M.Sc. (2002) and Ph.D. (2005) degrees from University of Cairo. At present, She is Associate Professor of organic chemistry in the Chemistry Department, Faculty of Science, University of Cairo. She joined the scientific school of Prof. A. S. Shawali in 1997 and conducted several research projects in the area of the chemistry of hydrazonoyl halides, enaminones and heterocyclic chemistry. She synthesized many bioactive heterocyclic compounds. She published 65 papers including one review article. 